\title{
DEPRESSION, ANXIETY AND STRESS LEVELS IN HEMODIALYSIS PATIENTS INFECTED WITH CHRONIC HEPATITIS B AND C
}

O. Farajli ${ }^{1}$

${ }^{1}$ Ministry of Health, Male Clinic, Baku, Azerbaijan

\section{Objectives:}

The purpose of this study is to compare the level of depression, anxiety disorder, and stress in hemodialysis patients with hepatitis virus infected with non-infected to viral hepatitis in hemodialysis patients.

\section{Background:}

Hemodialysis is a high-risk setting for transmission of hepatitis $B$ and $C$ viruses, as well as the spread of other infections transmitted by blood.

Although the measures are taken against Hepatitis B (HBV), like isolating the patients, preventive examination of blood test, preventive vaccination, etc., the Hepatitis $C$ virus (HCV) is continued to be a frequent case

\section{Materials and Methods:}

In this study, a comparative analysis of 34 patients infected with hepatitis viruses during a minimum of 2 years and two groups of patients in hemodialysis without hepatitis viruses was given. The Dass 21 test has been used for the analysis.

\section{Results and Conclusions:}

The group of patients contaminated to hepatitis $B$ and $C$ viruses

\begin{tabular}{||l||l|l|l||}
\hline & Depression & Anxiety & Stress \\
\hline Normal & 0 & 1 & 2 \\
\hline Mild & 18 & 15 & 19 \\
\hline Moderate & 9 & 13 & 10 \\
\hline Marked & 7 & 4 & 2 \\
\hline Severe (Major) & 1 & 1 & 1 \\
\hline
\end{tabular}

The group of patients in hemodialysis not contaminated to hepatitis viruses

\begin{tabular}{||l||l|l|l||}
\hline & Depression & Anxiety & Stress \\
\hline Normal & 11 & 8 & 10 \\
\hline Mild & 10 & 14 & 8 \\
\hline \hline Moderate & 8 & 10 & 8 \\
\hline Marked & 3 & 1 & 4 \\
\hline Severe (Major) & 2 & 1 & 4 \\
\hline
\end{tabular}

It can be seen from the table that the patients receiving hemodialysis contaminated to additional viral infections increase the present level of depression, stress, and anxiety disorder. In the absence of the monthly comparative investigations is the lack part of the study. 